\title{
Inpatient intervention with intensive contact after discharge improved smoking cessation rates
}

Miller NH, Smith PM, DeBusk RF, et al.Smoking cessation in hospitalized patients. Arch Intern Med 1997 Feb 24;157:409-15.

\section{Objective}

To compare an inpatient, multicomponent, smoking cessation intervention involving intensive or minimal telephone contact after discharge, with usual care.

\section{Design}

Randomised controlled trial with 12 month follow up.

\section{Setting}

4 community based hospitals in the USA.

\section{Patients}

2024 patients admitted to hospital who reported using tobacco products during the previous month. Exclusion criteria were admission to obstetrical or psychiatric wards, expected hospital stay $<36$ hours, inability to read or write English, plans to relocate, impaired consciousness, diagnosed alcohol or drug abuse, involvement in a myocardial infarction rehabilitation programme, or desire to quit on their own or not at all. 82 patients died during the course of the study. 1942 patients (mean age $51 \mathrm{y}, 68 \%$ white, $51 \%$ men) were included in the final analysis.

\section{Intervention}

Patients were allocated to intensive intervention $(n=561)$, minimal intervention $(n=473)$, or usual care $(n=990)$. All groups received standardised physician advice. Both intervention groups received a 30 minute, behavioural counselling session given by trained nurses at the bedside, an American Heart Association videotape, and an audiotape of relaxation exercises. Patients who met criteria for nicotine dependence were offered nicotine replacement therapy (NRT). The minimal group received a 10 minute telephone call 48 hours after discharge.
The intensive group received 4 telephone calls within 90 days after discharge, and those who relapsed were offered additional counselling. While in hospital, the usual care group received printed materials and a list of partially subsidised outpatient cessation programmes.

\section{Main outcome measure}

Confirmed smoking cessation at 12 months.

\section{Main results}

Patients in the intensive group had higher cessation rates than those receiving usual care $(27 \%$ v 20\%, $\mathrm{p}=0.009)$. Cessation rates were similar for the intensive group compared with the minimal group $(27 \% v 22 \%, \mathrm{p}=0.08)$, and the minimal group compared with usual care $(22 \% v 20 \%, \mathrm{p}=0.5)$ (table).

\section{Conclusion}

An inpatient, multicomponent intervention involving intensive telephone contact after discharge was more effective than usual care for smoking cessation.

Intensive intervention $v$ usual care*

\begin{tabular}{clllll}
\hline $\begin{array}{l}\text { Outcome at } \\
12 \text { months }\end{array}$ & $\begin{array}{l}\text { Intensive } \\
\text { EER }\end{array}$ & $\begin{array}{l}\text { Usual care } \\
\text { CER }\end{array}$ & $\begin{array}{l}\text { RBI } \\
(95 \% \text { CI })\end{array}$ & $\begin{array}{l}\text { ABI } \\
\mid \text { EER-CER } \mid\end{array}$ & $\begin{array}{l}\text { NNT } \\
(\text { CI })\end{array}$ \\
\hline $\begin{array}{c}\text { Smoking } \\
\text { cessation }\end{array}$ & $27 \%$ & $20 \%$ & $\begin{array}{l}32 \% \\
(9 \text { to } 59)\end{array}$ & $7 \%$ & $\begin{array}{l}16 \\
(9 \text { to 52) }\end{array}$
\end{tabular}

*Abbreviations in table defined in glossary; RBI, ABI, NNT, and CI are calculated from data in article.

Source of funding: National Heart, Lung, and Blood Institute.

For article reprint: Ms NH Miller, Stanford University School of Medicine, 780 Welch Road, Suite 106, Palo Alto, CA 94304, USA. Fax +1 4157236798

\section{Commentary}

This study by Miller et al is a sound attempt to evaluate a smoking cessation intervention for patients in hospital. Cessation rates were greater in the intensive intervention group, although some of this may be attributable to the higher level of NRT prescribed in this group (44\%) over the minimal intervention group (39\%) and the usual care group (29\%). NRT has previously been shown to augment cessation rates in smokers who are motivated to stop, and to alleviate withdrawal symptoms when combined with patient counselling. ${ }^{1}$

Cessation rates were higher in this study than in the only other published study of a similar group of patients, which reported intervention and usual care group cessation rates of $14 \%$ and $9 \%$ $(\mathrm{p}<0.05)$, respectively. ${ }^{2}$ The higher rates reported by Miller et al may be partly explained by the inclusion of only those patients who were motivated to stop smoking.

Nurses have an important role in encouraging patients to give up smoking. Clark $e t a p^{3}$ found that health education interventions initiated by nurses led to smoking cessation in $17 \%$ of those sampled, and another 12\% substantially reduced their cigarette consumption. Nurses often feel, however, that they lack appropriate training to do this effectively. ${ }^{4}$

Hospital admission can be a powerful incentive to stop smoking, and nurses are ideally placed to identify patients who are motivated to stop smoking, to initiate patient education by the bedside, and to provide telephone and face to face follow up and counselling.

\section{Sarah Fisher, RGN, MSc Lecturer, Cardiac Nursing Nightingale Institute, King's College London, UK}

1 Fiore MC, Kenford SL, Jorenby DE, et al. Two studies of the clinical effectiveness of the nicotine patch with different counseling treatments. Chest 1994;105:524-33.

2 Stevens VJ, Glasgow RE, Hollis JF, et al. A smoking-cessation intervention for hospital patients. Med Care 1993;31:65-72.

3 Clark JM, Haverty S, Kendall S. Helping people to stop smoking: a study of the nurse's role. $J$

4 Macleod-Clark J, Haverty S, Elliot K, et al. Helping people stop smoking: the nurse's role. Phase 1 . ing people stop smoking: the nurse's role. Phase 1 .
Reports $A, B$, and $\mathrm{C}$. London: University of Reports $A, B$, London, 1985. 